\title{
Reduction-oxidation pathways involved in cancer development: a systematic review of literature reviews
}

\author{
Xīn Gào ${ }^{1,2}$ and Ben Schöttker ${ }^{1,2,3}$ \\ ${ }^{1}$ Division of Clinical Epidemiology and Aging Research, German Cancer Research Center, Heidelberg, Germany \\ ${ }^{2}$ Network Aging Research, University of Heidelberg, Heidelberg, Germany \\ ${ }^{3}$ Institute of Health Care and Social Sciences, FOM University, Essen, Germany \\ Correspondence to: Ben Schöttker, email: b.schoettker@dkfz.de \\ Keywords: neoplasm; oxidative stress; redox signaling; signal transduction; reactive oxygen species \\ Received: November 04, $2016 \quad$ Accepted: April 03, $2017 \quad$ Published: April 16, 2017
}

Copyright: Gào et al. This is an open-access article distributed under the terms of the Creative Commons Attribution License 3.0 (CC BY 3.0), which permits unrestricted use, distribution, and reproduction in any medium, provided the original author and source are credited.

\section{ABSTRACT}

Oxidative stress results from an imbalance of the reactive oxygen species/ reactive nitrogen species (ROS/RNS) production and the oxidants defense system. Extensive research during the last decades has revealed that oxidative stress can mediate cancer initiation and development by leading not only to molecular damage but also to a disruption of reduction-oxidation (redox) signaling. In order to provide a global overview of the redox signaling pathways, which play a role in cancer formation, we conducted a systematic literature search in PubMed and ISI Web of Science and identified 185 relevant reviews published in the last 10 years. The 20 most frequently described pathways were selected to be presented in this systematic review and could be categorized into 3 groups: Intracellular ROS/RNS generating organelles and enzymes, signal transduction cascades kinases/phosphatases and transcription factors. Intracellular ROS/RNS generation organelles are mitochondria, endoplasmic reticulum and peroxisomes. Enzymes, including NOX, COX, LOX and NOS, are the most prominent enzymes generating ROS/RNS. ROS/RNS act as redox messengers of transmembrane receptors and trigger the activation or inhibition of signal transduction kinases/phosphatases, such as the family members of protein tyrosine kinases and protein tyrosine phosphatases. Furthermore, these reactions activate downstream signaling pathways including protein kinase of the MAPK cascade, PI3K and PKC. The kinases and phosphatases regulate the phosphorylation status of transcription factors including APE1/Ref-1, HIF-1a, AP-1, Nrf2, NF-KB, p53, FOXO, STAT, and $\beta$-catenin. Finally, we briefly discuss cancer prevention and treatment opportunities, which address redox pathways and further research needs.

\section{INTRODUCTION}

Reactive oxygen species (ROS) and reactive nitrogen species (RNS) are a battery of radical and non-radical molecules that can be produced by cellular metabolism or be induced by exogenous sources. The oxidative modification of crucial cysteine residues can lead to functional alterations of proteins, which may also have beneficial effects [1]. Therefore, ROS/RNS, especially hydrogen peroxide $\left(\mathrm{H}_{2} \mathrm{O}_{2}\right)$ and nitric oxide $(\mathrm{NO})$, can act as second messengers by activating or inhibiting protein functions [2-4]. There are various cellular activities that can be regulated by ROS/RNS via induction of redoxsensitive signal transductions [5, 6]. For instance, ROS play a part in antioxidant defense systems to maintain redox homeostasis even though they are strong oxidants themselves [3].

The term "oxidative stress" refers to an imbalance in which pro-oxidants overwhelm the capacity of antioxidant defense systems. Excessive levels of ROS/RNS are able to react with proteins, lipids and nucleic acids, and may exert negative effects on these molecules [3, 7]. Accumulating evidence has revealed that excessive levels of ROS/RNS can directly react with nucleic acids leading 
to mitochondrial and nucleus genomic instability, which facilitates the cancer process which in turn facilitates cancer [8]. Besides molecular damage, increased ROS/ RNS levels are involved in disruption of redox signaling and regulation [9]. In cancer biology, oxidative stress has been shown to underlay the hallmarks of cancer [10]. Oxidative stress induced disruption of signaling pathways may promote cancer cell survival, proliferation, invasion, angiogenesis, inhibition of apoptosis and chemo- and radio- therapy resistance $[9,11]$. Moreover, several population-based prospective studies observed that oxidative stress is a risk factor of some cancer sites $[12,13]$. Therefore, there is no doubt that redox signaling pathways provide opportunities to identify novel targets of cancer treatment and prevention [14]. The present systematic review identified, appraised and summarized published literature reviews from the last ten years in order to give a comprehensive overview of the redox regulation pathways involved in cancer etiology.

\section{RESULTS}

\section{Literature search and selection process}

A flowchart of the literature search and study selection process is shown in Figure 1. 1,022 articles were retrieved by application of the search strategy to Medline and ISI Web of Knowledge and 979 articles remained after exclusion of duplicate articles. In title and abstract as well as full-text screening, articles that met 1 of the exclusion criteria were excluded and 144 articles remained. Via cross-referencing and a specific search for each pathway, we identified 38 additional reviews leading to 185 articles eligible for inclusion in this review. The 38 pathways which were related to oxidative stress and have also been described to be involved in cancer development were mentioned by the 185 relevant articles. 20 of the 38

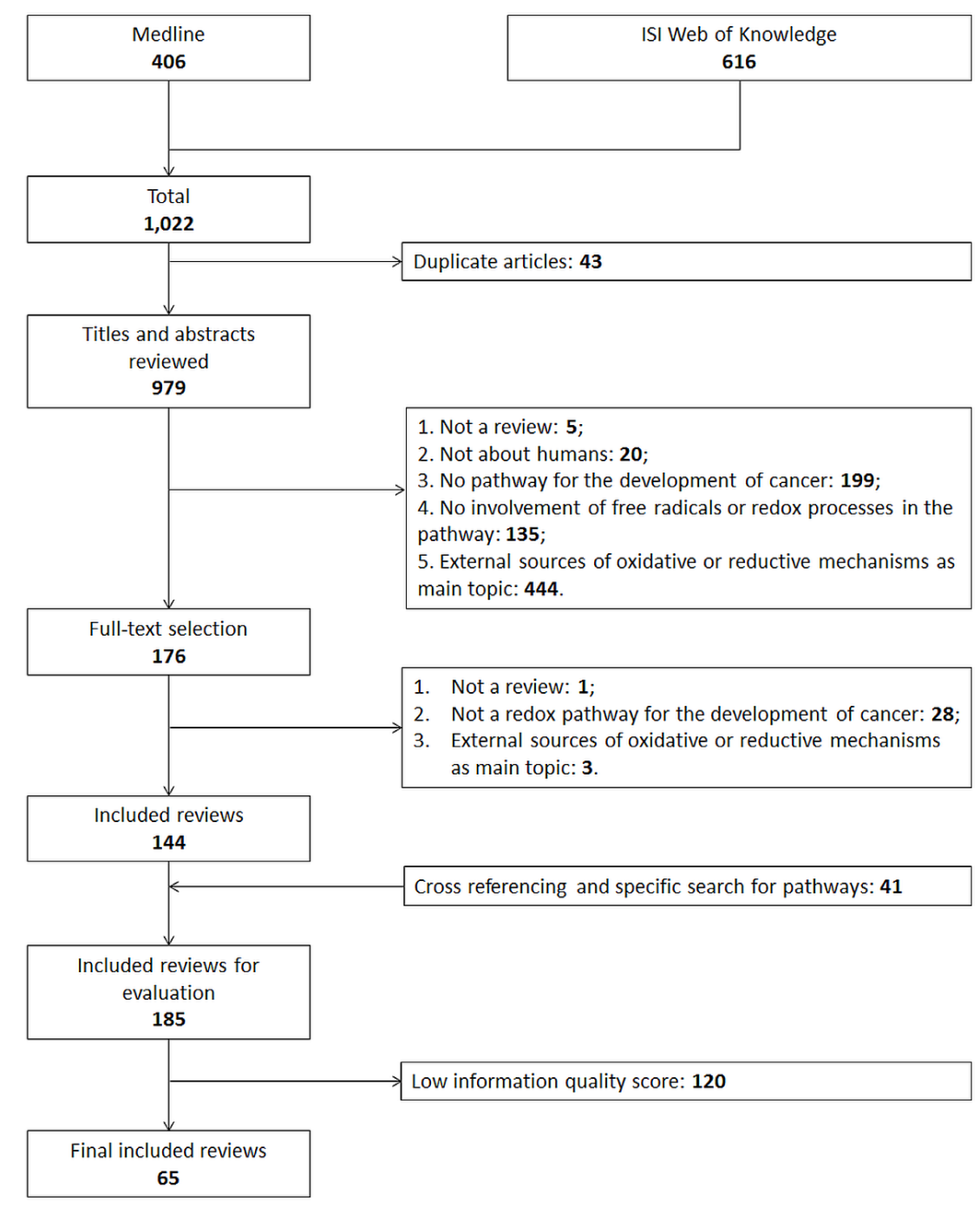

Figure 1: Flow chart of the systematic literature search. 
Table 1: Reduction-oxidation pathways involved in cancer development with frequency of appearance in reviews published 2005 - 2015.

\begin{tabular}{|c|c|c|c|c|}
\hline No & Name of pathway & $\begin{array}{l}\text { Frequency of appearance } \\
\text { in } 185 \text { included reviews }\end{array}$ & $\begin{array}{l}\text { Frequency of appearance in } 65 \\
\text { reviews with high information } \\
\text { quality score }\end{array}$ & $\begin{array}{l}\text { Selected } \\
\text { references }\end{array}$ \\
\hline \multicolumn{5}{|c|}{ Intracellular ROS/RNS generating organelles and enzymes } \\
\hline 1 & Mitochondria & 22 & 4 & {$[5,15-17]$} \\
\hline 2 & Endoplasmic reticulum & 3 & 1 & [5] \\
\hline 3 & Peroxisomes & 1 & 1 & {$[5]$} \\
\hline 4 & NADPH oxidase & 22 & 3 & {$[18-20]$} \\
\hline 5 & Cyclooxygenase & 6 & 3 & {$[21-23]$} \\
\hline 6 & Lipoxygenase & 6 & 3 & {$[21,22,24]$} \\
\hline 7 & Nitric oxide synthase & 6 & 3 & {$[25-27]$} \\
\hline 8 & Cytochrome P450 & 1 & 1 & {$[5]$} \\
\hline 9 & Xanthine oxidase and oxidoreductase & 1 & 1 & {$[5]$} \\
\hline 10 & Proline dehydrogenase & 1 & 1 & {$[28]$} \\
\hline \multicolumn{5}{|c|}{ Signal transduction cascades kinases/ phosphatases } \\
\hline 11 & Mitogen-activated protein kinase & 41 & 6 & [29-34] \\
\hline 12 & Phosphoinositide 3-kinase & 26 & 4 & {$[35-37]$} \\
\hline 13 & Protein tyrosine kinase & 10 & 4 & {$[37-40]$} \\
\hline 14 & protein tyrosine phosphatase & 16 & 4 & {$[37,40-42]$} \\
\hline 15 & Protein kinase $\mathrm{C}$ & 7 & 3 & {$[37,43,44]$} \\
\hline 16 & Protein kinase Hippo & 2 & 1 & {$[45]$} \\
\hline \multicolumn{5}{|c|}{ Transcription factors } \\
\hline 17 & Nrf2 & 29 & 4 & [46-49] \\
\hline 18 & $N F-\kappa B$ & 27 & 4 & {$[50-53]$} \\
\hline 19 & HIF & 22 & 4 & {$[54-57]$} \\
\hline 20 & P53 & 22 & 6 & {$[50,58-62]$} \\
\hline 21 & AP-1 & 21 & 4 & {$[37,63-65]$} \\
\hline 22 & FOXO & 16 & 4 & {$[62,66-68]$} \\
\hline 23 & STAT & 10 & 2 & {$[69,70]$} \\
\hline 24 & Wnt $/ \beta$-catenin & 7 & 4 & {$[58,71-73]$} \\
\hline 25 & APE1/Ref-1 & 6 & 2 & {$[74,75]$} \\
\hline 26 & Smad & 5 & 2 & {$[58,76]$} \\
\hline 27 & Yap1 & 4 & 1 & {$[6]$} \\
\hline 28 & Sp1 & 4 & 1 & {$[6]$} \\
\hline 29 & AhR & 2 & 1 & {$[6]$} \\
\hline 30 & Ets-1 & 3 & 1 & {$[16]$} \\
\hline 31 & Egr-1 & 1 & 1 & {$[6]$} \\
\hline 32 & Glucocorticoid receptor & 1 & 1 & {$[6]$} \\
\hline 33 & Paired box 5 & 1 & 1 & {$[6]$} \\
\hline 34 & Paired box 8 & 1 & 1 & [6] \\
\hline 35 & TTF-1 & 1 & 1 & [6] \\
\hline 36 & USF1 & 1 & 1 & [6] \\
\hline 37 & NFAT & 1 & 1 & {$[37]$} \\
\hline 38 & Myb & 1 & 1 & [37] \\
\hline
\end{tabular}

Abbreviations: AhR, Aryl hydrocarbon receptor; AP-1, Activator protein 1; APE1, Apurinic/apyrimidinic endonuclease, Ref1, Redox effector factor-1; Egr-1, Early growth response protein 1; Ets-1, E26 transformation-specific-1; FOXO, Forkhead box O; HIF, Hypoxia-inducible factor; Myb, Transcriptional activator Myb; NFAT, Nuclear factor of activated T-cells; NF$\kappa \mathrm{B}$, Nuclear factor- $\kappa \mathrm{B}$; Nrf2, Nuclear factor E2-related factor 2; P53, Tumor protein p53; Smad, Small mothers against decapentaplegic; Sp1, Specificity protein 1; STAT, Signal transducer and activator of transcription; TTF-1, Transcription termination factor 1; USF1, Upstream stimulatory factor 1; Yap1, Yes-associated protein 1. 
pathways were mentioned 5 times or more and rated as the prominent pathways. In order to base this review on high-quality reviews only, information quality of the 185 review articles was scored and 120 articles were excluded with scores lower than 6 points (Appendix B) leading to the final number of 65 reviews used to describe the prominent pathways in this review (Appendix C). Each of the 20 prominent pathways was mentioned in at least in 1 high-quality review. The 20 prominent pathways can be generally categorized into 3 groups: intracellular ROS/RNS generating organelles, intracellular ROS/RNS generating enzymes, signal transduction cascades kinases/ phosphatases and transcription factors (Table 1).

\section{Intracellular ROS/RNS generating organelles and enzymes}

Oxidants can be produced by organelles as well as enzyme activities. Organelles that can generate ROS are mitochondria, endoplasmic reticulum and peroxisomes. Intracellular oxidase and oxygenase can also generate ROS/RNS (Figure 2). The mechanisms indicated in Figure 2 are described briefly in the following chapters.

\section{Mitochondria}

Mitochondria are critical for ATP biosynthesis through oxidative phosphorylation in normal cells. ROS are generated as a consequence of mitochondrial proton and electron leak which occurs in the electron transport chain (ETC) $[5,16]$. The ETC consists of 5 protein complexes among which NADH-ubiquinone oxidoreductase (complex I) and ubiquinone-cytochrome c oxidoreductase (complex III) are the most investigated ROS-generating sites. Electrons are transferred from a donor molecule to an acceptor molecule during which electrons escape from ETC and are received by oxygen. Thus, oxygen is reduced to superoxide anion (O2-) which is then catalyzed to hydrogen peroxide $\left(\mathrm{H}_{2} \mathrm{O}_{2}\right)$ by superoxide dismutase. Under physiological conditions $\mathrm{H}_{2} \mathrm{O}_{2}$ acts as a messenger that is essential to maintain cellular redox status [16].

Mitochondrial disruption has been found in a wide range of cancer types. Mitochondria in cancer cells generate more superoxide anions when compared to their normal counterparts [17]. It has been shown that cancer transformation induces aerobic glycolysis, which accelerates cancer cell adaption to hypoxia [15, 17]. The greater ROS stress may result from mitochondrial dysfunction and lead to oxidative damage to mitochondrial DNA (mtDNA) and nuclear DNA (nDNA) [15, 17]. Unrepaired lesions may cause oxidative phosphorylation of genes resulting in mutations which further result in an alteration of mitochondrial metabolism and bioenergetics [17]. Besides gene mutation, high levels of ROS leads to downstream pathway activation that makes cancer cells adapt to hypoxia and supports cancer cell survival [15, $17]$.

\section{NADPH oxidases (NOX)}

NADPH oxidases (NOX) are widely expressed in tissues and anchored to the plasma membrane. The

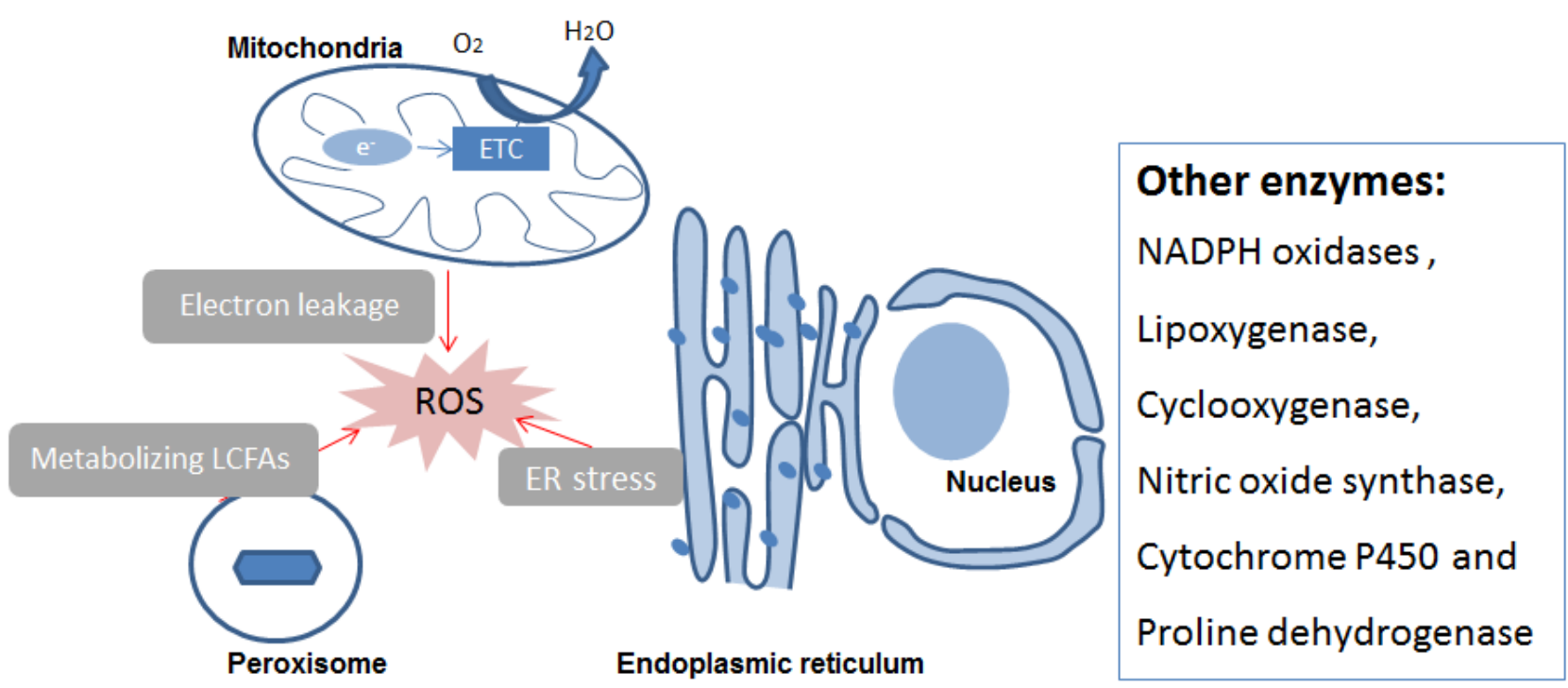

Figure 2: Intracellular ROS/RNS sources. Abbreviations: ER, endoplasmic reticulum; ETC, Electronic transport chain; LCFAs, Long-chain fatty acids, ROS Reactive Oxygen Species. 
NOX family comprises 7 enzymes: NOX1-5 and dual oxidase1-2 (DUOX1-2) [18]. The isoforms can be divided into 2 categories by the types of ROS generation. NOX13 and NOX5 catalyze superoxide generation while DUOX1-2 and NOX4 promote $\mathrm{H}_{2} \mathrm{O}_{2}$ production [18]. NOX-mediated ROS production can be facilitated by numerous stimuli and regulated by the interaction between NOX and a battery of intracellular proteins [18, 20]. The stimuli of mammalian NOX can be generally categorized into 4 groups: chemical factors, physical factors, changed cellular environments and inflammatory factors [20]. The recruitment of cytoplasm and membrane associated proteins help NOX to improve its structural stability and activity [18].

It has been found that NOX isoforms are overexpressed in several types of cancer, indicating that NOX may promote cancer development. NOX family molecules could contribute to carcinogenesis by promoting oxidative stress and regulating cell signaling [18]. It has been shown that NOX activities are involved in regulation of cellular signaling pathways, such as Nrf2, p38 MAPK, JAK-STAT, PI3K-AKT and RAS-RAF-MEK-
ERK [19]. For example: overexpression of NOX1 inhibits tumor suppressor p53 and activates NF- $\kappa \mathrm{B}$ signaling, which may promote cancer development $[18,19]$.

\section{Cyclooxygenases (COX) and lipoxygenases (LOX)}

Cyclooxygenases (COX) and lipoxygenases (LOX) mediate $\omega-6$ polyunsaturated fatty acid metabolism during which ROS are generated. The overexpression of COX and LOX in certain cancers, such as prostate, colorectal, lung, breast and pancreatic cancers, implies a potential involvement in carcinogenesis [21-24].

$\mathrm{COX}$ is also known as prostaglandin-endoperoxide synthase. The COX family consists of 3 isoforms: COX$1, \mathrm{COX}-2$ and COX-3. COX-1 is constitutively active in multiple tissues, while COX-2 is generally undetectable in most tissues and can be induced by inflammatory stimuli and tumor promoters. COX-3 is regarded as an alternate splice variant of $\mathrm{COX}-1$, but does not function in humans [22]. Both COX-1 and COX-2 can catalyze the two-steps synthesis of prostaglandin $\mathrm{H} 2$ from

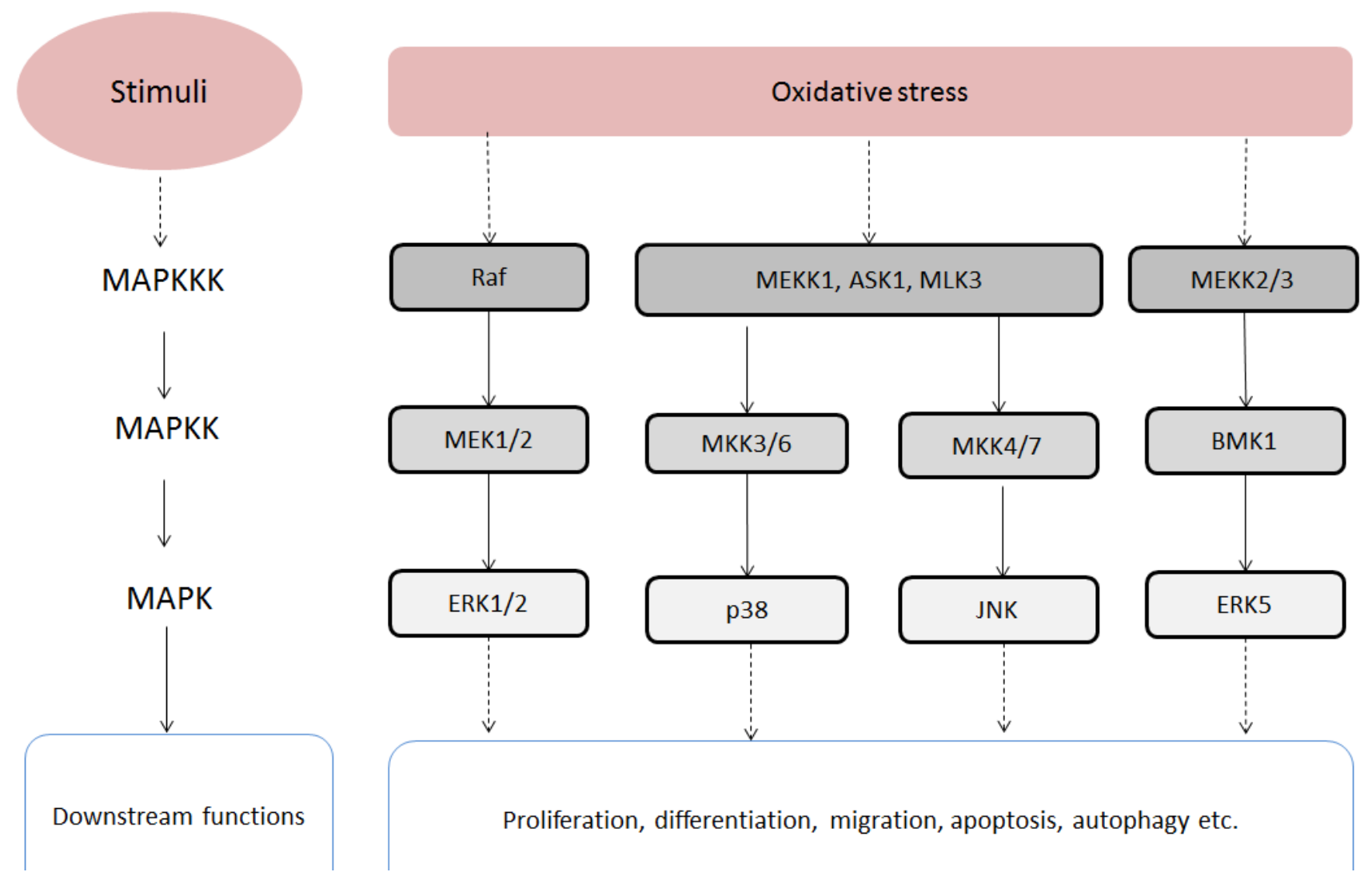

Figure 3: Oxidative stress-stimulated MAPK signalling pathways. Abbreviations: ASK1, Apoptosis signal-regulating kinase 1; BMK1, Big mitogen-activated protein kinase 1; ERK1/2, Extracellular signal-regulated kinase 1/2; ERK5, Extracellular signal-regulated kinase 5; JNK, c-Jun N-terminal kinases; MAPK, Mitogen-activated protein kinase; MAPKK, MAPK kinase; MAPKKK, MAPK kinase kinase; MEK1, MAPK/ERK kinase 1; MEK2, MAPK/ERK kinase 2; MEKK1, MAPK/ERK kinase kinase 1; MEKK2, MAPK/ERK kinase kinase 2; MEKK3, MAPK/ERK kinase kinase 3; MKK3/6, MAPK kinase 3/6; MKK4/7, MAPK kinase 4/7; MLK3, mixed-lineage protein kinase 3; p38, P38 mitogen-activated protein kinase. 
arachidonic acid. During this process arachidonic acid is oxidized to prostaglandin G2 which is then reduced to prostaglandin H2 [21]. Prostaglandin H2 is the precursor of eicosanoids which function as regulators in multiple molecular events and also play a role in promoting tumor growth and suppressing tumor immunity [21, 22]. In addition, the COX pathways can produce ROS, such as lipid hydroperoxides, and consume reduced glutathione, which leads to oxidative stress [21]. The increased ROS concentration in turn activates COX-2 [23].

In terms of LOX, 6 functional enzymes have been identified in humans, namely 5-LOX, 12-LOX, 12R-LOX, 15-LOX, 15-LOX-2 and eLOX-3 [22]. Similar to COX, LOX is able to catalyze conversion of arachnoid acid to eicosanoids and promote carcinogenesis [21, 22]. For instance, 5-LOX, the most extensively studied isoenzyme, is mainly expressed in cells of myeloid origin and has been found overexpressed in tumors [24]. 5-LOX has been shown to catalyze the conversion of arachnoid acid to 5(S)-Hydroxyicosatetraenoic acid [5(S)-HPETE] which is subsequently converted to leukotriene A4 (LTA4) [24]. These eicosanoids play a part in cell proliferation and angiogenesis [22].

\section{Nitric oxide synthases (NOS)}

Nitric oxide (NO) is a multifunctional signaling molecule mediating the $\mathrm{p} 53, \mathrm{NF}-\kappa \mathrm{B}, \mathrm{PI} 3 \mathrm{~K}-\mathrm{AKT}, \mathrm{Wnt} / \beta-$ catenin and MAPK pathways $[26,27]$. NO is synthesized by nitric oxide synthases (NOS), which catalyze the synthesis of NO from L-arginine, NADPH and oxygen. The enzymatic family includes 3 isoforms: neuronal NOS (nNOS), endothelial NOS (eNOS) and inducible NOS (iNOS). nNOS and eNOS are constitutively expressed in neuronal cells and vascular endothelial cells, respectively. The expression is dependent upon intracellular calcium

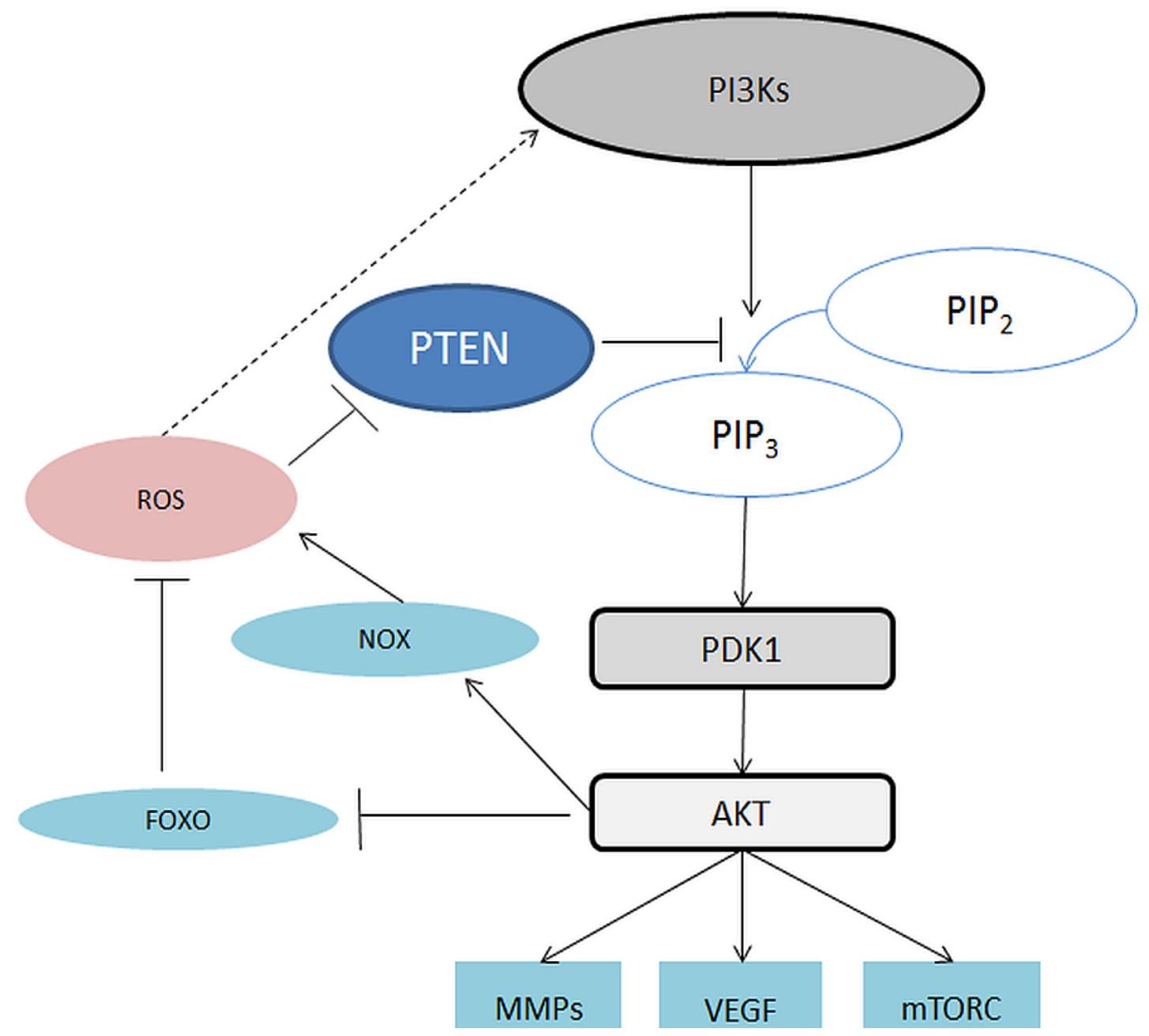

Figure 4: Schematic of the PI3K/AKT signalling pathway. Abbreviations: AKT, also known as protein kinase B, PKB; FOXO, Forkhead Box O; MMP, Matrix metalloproteinase; mTORC, mammalian Target of Rapamycin Complex; NOX, NADPH Oxidase; PDK1: Phosphoinositide-Dependent Kinase-1; PIP2, Phosphatidylinositol 4,5-bisphosphate; PIP3, Phosphatidylinositol-3,4,5-trisphosphate; PTEN, Phosphatase and tensin homolog; ROS, Reactive Oxygen Species; VEGF, Vascular Endothelial Growth Factor. 
levels explaining why they are also termed constitutive NOS (cNOS). However, it has been observed that cNOS can also be induced by immunological stimuli and have wider distribution [28]. iNOS is predominantly distributed in macrophages and neutrophils. As the name suggests, iNOS is inducible by inflammatory cytokines, endotoxin, hypoxia and oxidative stress. In general, iNOS generates more NO for longer intervals [28].

NOSs are also expressed in malignant tumors [26]. However, NO plays quite a complex role in tumors and it depends on the concentrations, timing, location and presence of other free radicals $[26,27]$. In normal cells, NO derived from iNOS mediates chronic inflammation, which may promote neoplastic transformation [26]. In tumor cells, lower levels of NO can prevent some types of tumor cells from apoptosis. However, higher NO concentrations can be toxic to tumor cells [27]. For instance, in vascular endothelial cells, moderate NO derived from eNOS functions, activates matrix metalloproteinase family molecules via the RAS-RAFMEK-ERK pathway facilitating angiogenesis [25].

\section{Other intracellular ROS/RNS generating sources}

The endoplasmic reticulum and peroxisomes are also organelle sources of ROS/NOS, as shown in Figure 2. They are described in detail in the review of
Holmstrom and Finkel [5]. In brief, the endoplasmic reticulum is a well-orchestrated protein-folding organelle and can produce ROS as by-products. ROS generation is increased during endoplasmic reticulum stress in response to accumulation of misfolded and unfolded proteins. Peroxisome is involved in various biochemical processes and it can produce ROS as part of their role in metabolizing long-chain fatty acids. For less prominent intracellular ROS/RNS generating enzymes, we refer interested readers to other reviews. Holmstrom and Finkel [5] give an overview on cytochrome P450 as well as xanthine oxidase and oxidoreductase. Another enzyme, proline dehydrogenase, is discussed in the review of Liu and Phang [28].

\section{Signal transduction cascades kinases/ phosphatases}

Generally, ROS/RNS interact with some certain amino acid residues of proteins (protein tyrosine phosphatases (PTPs), protein tyrosine kinases (PTKs) and protein kinase $\mathrm{C}(\mathrm{PKC})$ and in turn activate downstream kinase cascades (phosphoinositide 3-kinase (PI3K) and mitogen-activated protein kinases (MAPKs). They function as a switch of downstream proteins in many cellular functions and detailed mechanisms are described below.

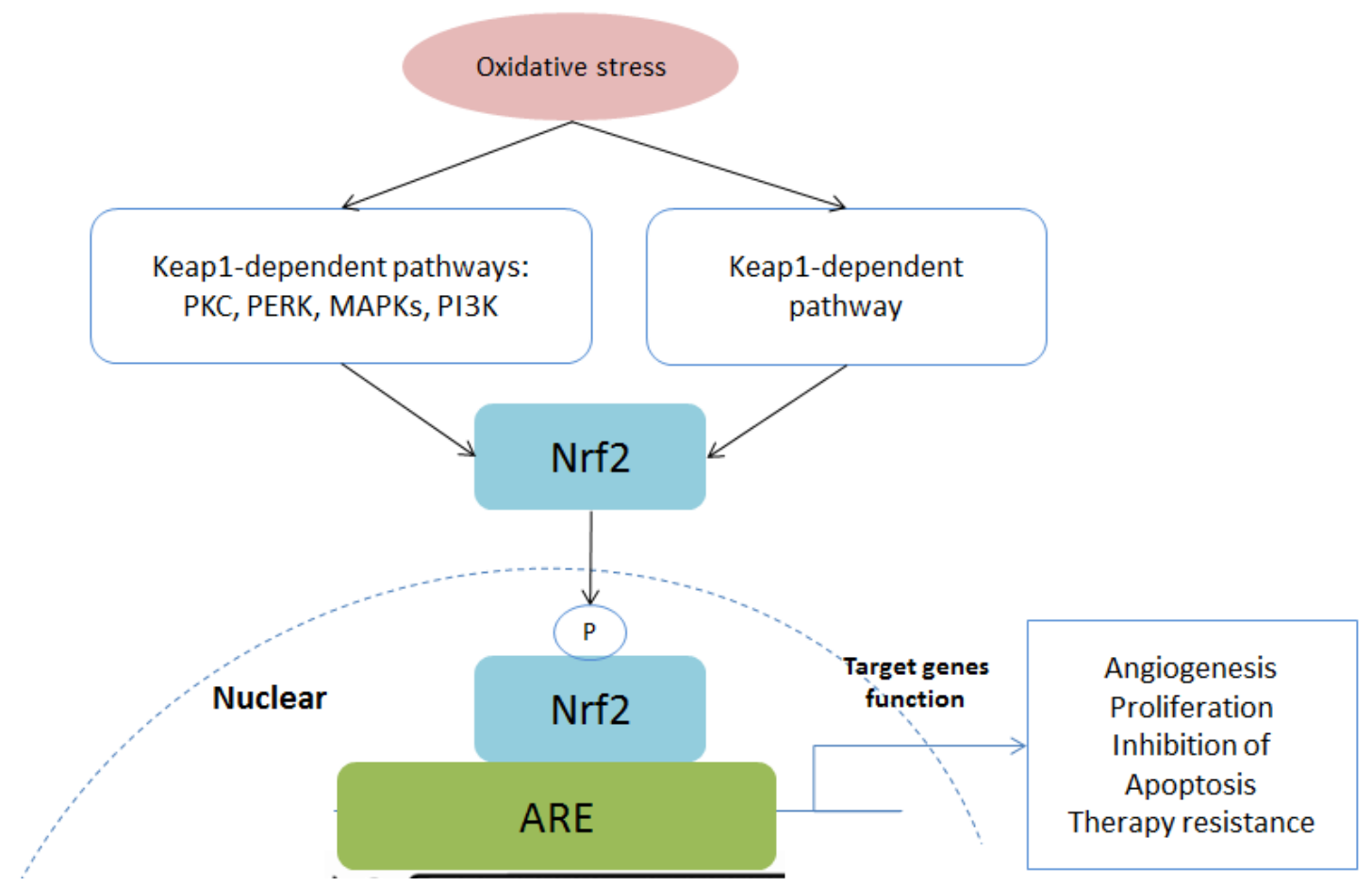

Figure 5: Schematic of the Keap1-Nrf2-ARE pathway. Abbreviations: AKT, also known as protein kinase B, PKB; FOXO, Forkhead Box O; MMP, Matrix metalloproteinase; mTORC, mammalian Target of Rapamycin Complex; NOX, NADPH Oxidase; PDK1: Phosphoinositide-Dependent Kinase-1; PIP2, Phosphatidylinositol 4,5-bisphosphate; PIP3, Phosphatidylinositol-3,4,5-trisphosphate; PTEN, Phosphatase and tensin homolog; ROS, Reactive Oxygen Species; VEGF, Vascular Endothelial Growth Factor. 


\section{Mitogen-activated protein kinases (MAPKs)}

The mitogen-activated protein kinase (MAPK) signaling pathways modulate a wide range of cellular responses, such as proliferation, differentiation, migration, apoptosis and autophagy [30]. MAPKs can be activated by many stimuli and activation can have numerous consequences. Therefore, the roles of the MAPK signaling pathways in cancer development are complex and pleiotropic [31]. Typically, the MAPK signaling pathways consist of 3 sequential kinases: a MAPK kinase kinase (MAPKKK) activates a MAPK kinase (MAPKK) which subsequently activates a MAPK (Figure 3) [30]. There are 4 MAPK family members, which are activated by ROS, including Extracellular Regulated Kinases 1/2 (ERK1/2), Jun N-terminal Kinases (JNKs), P38 mitogen-activated protein kinases (p38) and Big MAPK Kinase 1 (BMK1) [29].

The ERK1/2 signaling pathway, also referred to as the RAS-RAF-MEK-ERK pathway, is an extensively studied MAPK pathway. Oxidative stress is able to induce ERK activation through the RAS-RAF-MEK-ERK kinases axis [29]. The activation of ERKs modulates several cellular activities, such as cell survival, cell proliferation, cell migration and differentiation $[29,30]$. Therefore, the ERK1/2 pathway can promote cancer development by maintaining cancer cell survival and stimulating cancer cell proliferation and metastasis [30, 34]. In addition, mutations in genes which encode for RAS and RAF are involved in cancer development [34].

The JNK and p38 MAPK pathways have common upstream regulators and can be activated by oxidative stress [33]. They also interact with each other at the level of downstream targets which have been linked to cell proliferation, differentiation, survival and migration [33]. In the p38 MAPK signaling pathway, ROS/RNS can activate the p38 MAPK pathway by activating MAPK/ ERK kinase kinase 1 (MEKK1), mixed-lineage protein kinase 3 (MLK3) and apoptosis signal-regulating kinase 1 (ASK1). Then the MAPKKKs in turn activate MAPK kinase 3 and MAPK kinase 6 (MAP2K3/6) $[29,30]$. The activated p38 MAPK targets multiple transcription factors, such as p38, MEF2 and ATF-2 [34]. In the JNK signaling pathway, ROS can induce the activation of ASK1 and MAP3K1 which are MAPKKK. Then the MAPKKK activate MAP2K4/7 which subsequently activates JNKs.

\section{C-terminal region}

\section{$\mathrm{N}$-terminal region}

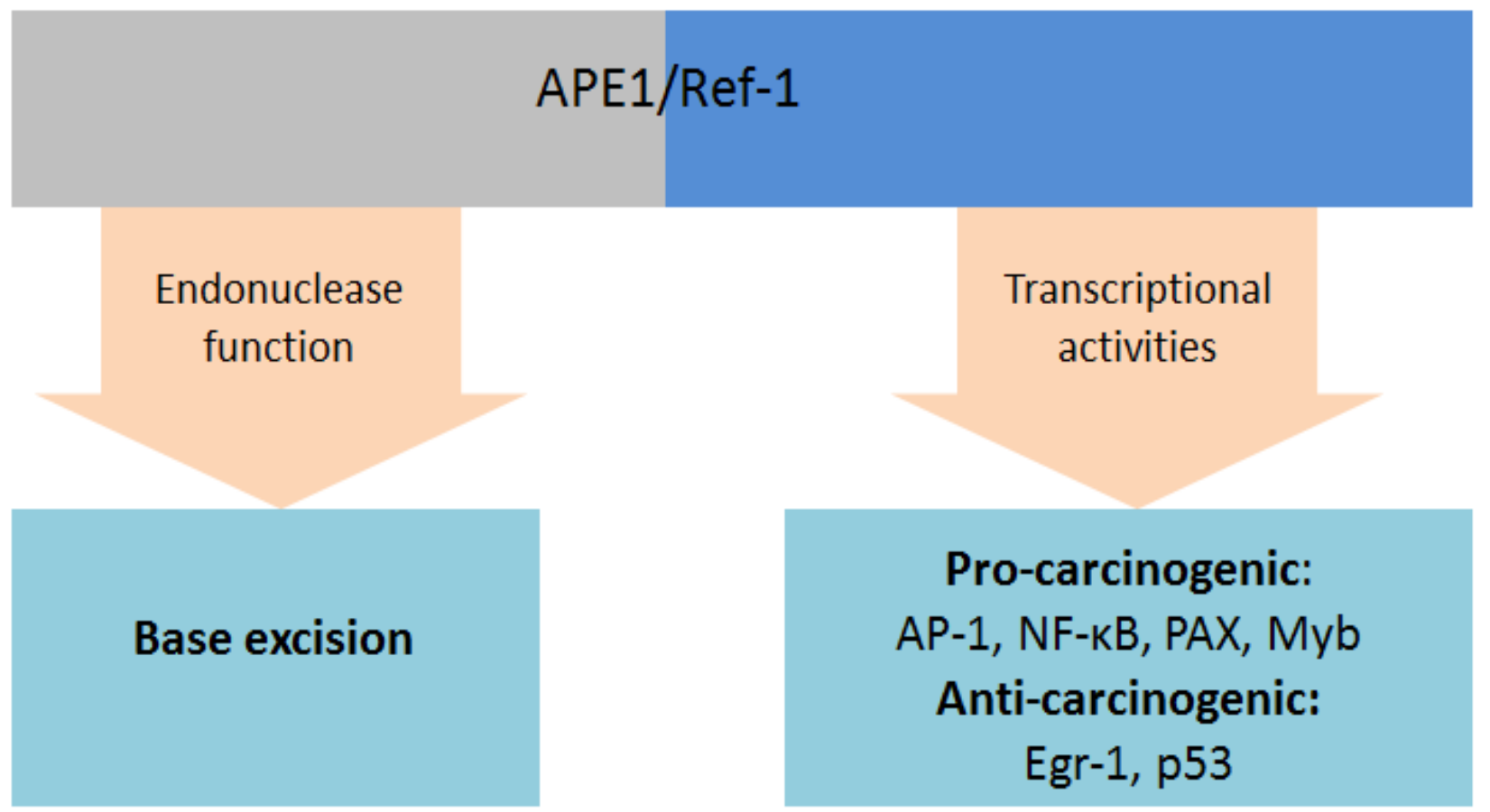

Figure 6: Functions of APE1/Ref-1. Abbreviations: AP-1, Activator protein 1; APE1, Apurinic/apyrimidinic endonuclease; Ref-1, Redox effector factor-1; Egr-1, Early growth response protein 1; Myb, Transcriptional activator Myb; NF- $\kappa B$, Nuclear factor- $\kappa$ B; PAX, Paired box; P53, Tumor protein p53. 
Similar to p38 MAPK, the activated JNKs are able to phosphorylate several transcription factors, like c-Jun, ATF-2 and STAT3 [29]. However, the p38 MAPK and JNK pathways produce contradictory effects on cell proliferation, apoptosis and differentiation in different cell contexts [33].

The most recently discovered MAPK pathway is the BMK1 signaling pathway which can also be induced by oxidative stress. This pathway is similar to the mentioned MAPK pathway with MEKK2/3 activating MAP2K2 and MAP2K2 subsequently activating BMK1 [29, 32]. Experimental evidence implies that the BMK1 signaling pathway is promoting angiogenesis and metastasis in cancer [32].

\section{Phosphoinositide 3-kinase (PI3K)/AKT}

In humans, the phosphoinositide 3-kinase (PI3K) family includes a variety of enzymes which have been divided into 3 classes: class I, class II and class III. We discuss herein class I which is the most investigated class involved in cancer development. The PI3Ks signaling pathway is triggered by growth factors and, in some cases, by ROS (Figure 4) [37]. The activated PI3Ks then phosphorylate phosphatidylinositol-4,5-bisphosphate (PIP2) to phosphatidylinositol-3,4,5-trisphosphate (PIP3) which acts as a signaling molecule to recruit pleckstrin homology domain containing proteins, such as phosphoinositide-dependent kinase-1 (PDK1) and protein kinase B (PKB, also known as AKT) [36]. The PI3K/AKT signaling pathway can be downregulated by phosphatase and tensin homolog (PTEN), which can dephosphorylate PIP3 back to PIP2 [77]. However, PTEN can be oxidized and inhibited by $\mathrm{H}_{2} \mathrm{O}_{2}$ resulting in activation of the $\mathrm{PI} 3 \mathrm{~K} /$ AKT signaling pathway.

The activation of AKT is involved in multiple cellular activities. For instance, AKT is involved in the activation of NOX, an enzyme generating ROS [77]. In addition, AKT mediates inhibition of forkhead box $\mathrm{O}$ (FOXO). The inactivation of FOXO also results in inhibition of apoptosis, which favors cancer growth [35]. AKT signaling, which has been shown to modulate many downstream pathways, is one of the major mediators of the PI3K pathway [35]. The hyperactivation of the PI3KAKT pathway is regarded as a hallmark of cancer. The activation of the PI3K-AKT signaling pathway is engaged in the inhibition of apoptosis as well as the promotion of proliferation and angiogenesis [36]. AKT can induce stimulation of mammalian target of rapamycin complex 1 (mTORC1) which promotes synthesis of proteins and cell survival $[35,36]$. In addition, AKT signaling contributes to angiogenesis and metastasis by triggering the vascular endothelial growth factor pathway (VEGF) and promoting the secretion of matrix metalloproteinase (MMP) [35]. MMP supports metastasis and invasion of cancer cells [78].

\section{Protein tyrosine kinases (PTKs) and protein tyrosine phosphatases (PTPs)}

Protein tyrosine kinases (PTKs) have been found to be hyperactivated in many cancer cells and are regarded as oncoproteins. The PTK superfamily is composed of 2 large enzyme families: the receptor tyrosine kinases (RTK) family (with 7 subfamilies) and the cytoplasmic non-receptor tyrosine kinases (NRTK) family (with 9 subfamilies) [37-40]. RTK isoforms are anchored to the plasma membrane and behave as cell surface receptors for various signaling molecules including $\mathrm{H}_{2} \mathrm{O}_{2}[37,40]$.

Integrin-mediated RTK activation is involved in regulating cancer cell division, adhesion, angiogenesis, motility and survival [39]. An example of RTK is the vascular endothelial growth factor receptor family which binds to vascular endothelial growth factor and induces vasculogenesis and angiogenesis in solid tumors [38]. NRTK isoforms are found in the cytoplasm and function as downstream targets of RTKs. They are vital components in various cancer promoting signaling pathways, such as the MAPK and PI3K pathways [39] (see also previous chapters). Through the activation of these pathways, NRTKs facilitate cancer cell transformation, proliferation and migration and inhibit apoptosis [39]. For instance the Src family kinases, which belong to the largest subfamily of NRTKs, are activated in a wide variety of cancer sites [39].

The term PTP defines a superfamily of more than 100 enzymes consisting of 2 subgroups: classical phosphotyrosine (pTyr)-specific phosphatases (classical PTPs) and dual specificity phosphatases [41]. There are several mechanisms involved in PTP regulation, including oxidation [41]. It has been found that ROSmediated oxidation can result in inactivation of PTPs. PTPs are involved in modulation of signaling pathways in coordination with PTK [41]. It has been shown that PTPs negatively regulate PTKs $[37,40]$. Therefore, ROS can indirectly activate PTKs via inactivating PTPs [37, 40]. Some PTPs behave as tumor suppressors [41]. For example, phosphatase and tension homolog, which is one of the most described dual specificity phosphatases, can mediate downregulation of the PI3K pathway resulting in tumor-cell death ([41], see also the chapter "Phosphoinositide 3-kinase (PI3K)/AKT"). There are also some PTPs that upregulate RTK signaling and function as cancer promoters [42]. One of the oncogenic PTPs is SHP2 that activates the Src family kinases by dephosphorylating a C-terminal binding site [42].

\section{Protein kinase C (PKC)}

Protein kinase $\mathrm{C}$ (PKC) comprises a large family of serine/threonine kinases with 3 subfamilies, which are: conventional PKCs, novel PKCs and atypical PKCs. ROS/ 
RNS can modulate PKCs by modifying the cysteine-rich zinc-finger regions of PKCs. $\mathrm{H}_{2} \mathrm{O}_{2}$ for example, activates PKC by inducing phosphorylation [44]. PKCs are not only regulated by ROS but are also related to ROS production. PKCs activation promotes the activity of NOX, which increase the level of ROS [37].

Activated PKC isozymes are also involved in many cellular signaling pathways by phosphorylating downstream proteins [44]. It has been shown that PKCs are upregulated in several types of cancer cells [43]. They are implicated in cancer cell survival, proliferation, invasion, metastasis, angiogenesis and apoptosis [43, 44]. However, whether PKCs promote or inhibit cancer development is dependent on cell context such as the isoform of PKC and the type of cancer [43]. PKC $\alpha$, a member of the conventional PKC subfamily, acts as a promoter of cell survival by regulating activation of $\mathrm{NF}-\kappa \mathrm{B}$. Another example is PKC $\delta$ which is engaged in promoting apoptosis by regulating the MAPK pathway [44].

\section{Other signal transduction cascades kinases/ phosphatases}

For the less prominent signal transduction cascade kinase protein kinase Hippo we would like to refer interested readers to the review of Qin et al. [45].

\section{Transcription factors}

Transcription factors are proteins that regulate target gene expression. The ROS-regulated transcription factors introduced in this chapter are Nrf2, NF- $\mathrm{B}$, HIFs, P53, AP-1, FOXO, STATs, $\beta$-catenin, APE1/Ref-1 and Smad proteins. ROS/RNS regulate these transcription factors through activation of protein kinases, inactivation of phosphatases or direct redox reaction with transcription factors [6].

\section{Nuclear factor E2-related factor 2 (Nrf2)}

Nuclear factor E2-related factor 2 (Nrf2) is a bZIP protein and plays a central role in the Kelch-like ECH-associated protein 1 (Keap1)-Nrf2-ARE pathway (Figure 5). This pathway is involved in the regulation of antioxidant proteins that protect cells against oxidative stress [46-49]. Keap1 is an important inhibitor of this pathway. The formation of a Keap1-Nrf2 complex leads to degradation of Nrf2. However, oxidative stress or electrophilic stress results in dissociation of the Keap1Nrf2 complex facilitating Nrf2 activation. In addition, Nrf2 can also be activated by oxidative stress via the PI3K, PKC and MAPK pathways [46]. Then Nrf2 proteins translocate into the nucleus and bind to the antioxidant response element (ARE) leading to target gene expression [46]. The Nrf2 is a master regulator of antioxidants, such as glutathione, heme oxygenase-1, catalase, superoxide dismutase and thioredoxin [46-49]. Besides antioxidants, the activation of Nrf2 results in expression of proteins which are responsible for anti-apoptosis. For instance, $\mathrm{Bcl}-2$, a downstream protein of $\mathrm{Nrf} 2$, is an inhibitor of apoptosis [47].

However, Nrf2 has a dual role in cancer development and progression [46, 47, 49]. As mentioned previously, Nrf2 maintains intracellular redox homeostasis and prevents normal cells from conversion into cancer cells. Nrf2 is a cancer suppressor when it is activated in normal cells. However, it has been shown that Nrf2 proteins are overexpressed in cancer cells [46]. The hyperactivated Nrf2 contributes to overexpression of target genes, leading to cancer cell survival and proliferation [46-49]. In addition, Nrf2 helps cancer cells to resist chemotherapy and radiotherapy $[46,49]$. Therefore, Nrf2 behaves as a cancer-promoter in cancer cells.

\section{Nuclear factor- $\kappa \mathrm{B}(\mathrm{NF}-\kappa \mathrm{B})$}

Nuclear factor- $\kappa \mathrm{B}(\mathrm{NF}-\kappa \mathrm{B})$, which are ubiquitous in mammalian tissues, regulate expression of numerous inflammatory mediators and act as core factors in multiple immune responses. This proteins family consists of 5 members: RelA (p65), RelB, c-Rel, NF-кB1 (p50/p105)

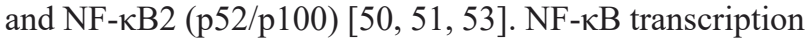
factors have the same conserved N-terminal Rel homology domain and can interact with each other forming up to 15 homo- and heterodimeric complexes [51]. In resting cells, the transcriptional function of NF- $\kappa \mathrm{B}$ dimers is blocked by a set of proteins, such as inhibitor of kappa $B(\mathrm{I} \kappa \mathrm{B})$ family proteins $(\mathrm{I} \kappa \mathrm{B} \alpha, \mathrm{I} \kappa \mathrm{B} \beta$ and $\mathrm{I} \kappa \mathrm{B} \varepsilon), \mathrm{p} 50$ and p52 [51]. It has been shown that the NF- $\kappa \mathrm{B}$ pathway can be stimulated by oxidative stress via activation of I $\kappa \mathrm{B}$ kinases (IKKs) [51-53]. Once stimulated, the NF- $\kappa B$ pathway upregulates the expression of target genes in apoptosis, proliferation and immune response $[51,52]$. In addition, the $\mathrm{NF}-\kappa \mathrm{B}$ pathway interacts with other redox signaling pathways, such as the JNK pathway.

$\mathrm{NF}-\kappa \mathrm{B}$ genes have been recognized as protooncogenes $[50,52,53]$. It has been observed that NF- $\kappa B$ dimers are constitutively active in several types of cancer cells, which accelerates cancer cell proliferation, invasion, metastasis, angiogenesis and inhibition of apoptosis [52]. For instance, NF- $\kappa \mathrm{B}$ activation increases the expression of MMP-9 promoting metastasis and invasion [52, 53]. Activated NF- $\kappa$ B dimers can also upregulate the epithelial growth factor inducing proliferation [52]. In addition, it has been shown that chemotherapeutic agents and ionizing radiation stimulate $\mathrm{NF}-\kappa \mathrm{B}$ dimers activation leading to resistance against these therapies $[52,53]$. 


\section{Hypoxia-inducible factors (HIFs)}

Hypoxia-inducible factor (HIFs) consist of the 3 isoforms HIF-1, HIF-2 and HIF-3. Each of the HIFs has 2 subunits, $\alpha$ and $\beta$. HIF- $1 \alpha$ is a transcription factor that is ubiquitous in mammalian cells and acts as an essential mediator in response to a low oxygen microenvironment [57]. In normoxia, prolyl hydroxylases hydroxylate 2 prolines on HIF- $1 / 2 \alpha$ inducing ubiquitination and degradation of HIF-1/2 $\alpha$ [57]. Hypoxia can induce inhibition of prolyl hydroxylases leading to dimerization of HIF- $1 / 2 \alpha$ and HIF- $1 / 2 \beta$. The HIF heterodimer regulates expression of target genes [57]. ROS/RNS have been shown to regulate HIF- $1 \alpha$ activity through the PI3K and MAPK cascade pathways [55]. Increased ROS/RNS levels induce stabilization, accumulation and activation of HIF-1 $\alpha$ even in normoxia [57]. It has been suggested that HIF-1 $\alpha$ is overexpressed in different tumor types and is implicated in excessive vascularization and tumor invasiveness [55]. For example, HIF-1 $\alpha$ upregulates the expression of vascular epidermal growth factors which stimulate angiogenesis in cancer [55]. HIF-2 $\alpha$ also represents transactivation activity. However, it is expressed in more restricted cell types and functions differently when compared to HIF-1 [56]. Hypoxia in tumors leads to overexpression of HIF-2 $\alpha$ which subsequently favors cancer cell survival, proliferation and metastasis [56]. Knowledge about HIF-3 $\alpha$ is limited because of the diversity of HIF-3 $\alpha$ variants [54]. It has been shown that several HIF- $3 \alpha$ variants regulate HIF$1 / 2 \alpha$ activities negatively [54].

\section{Tumor protein $\mathbf{p 5 3}$}

Tumor protein p53 is a vital redox-sensitive transcription factor that exerts suppressor effects on cancer development. It has been shown that oxidative stress can change the intracellular concentrations and subcellular localization of the $\mathrm{p} 53$ protein $[50,58,62]$. ROS cause oxidative modification of p53 cysteine residues affecting its transcriptional activity [59]. In addition, oxidative stress induces p53 activation by stimulating several signaling pathways (APE1/Ref-1, ASK1-p38 MAPK and PTPs-PKC $\delta$ pathways) [62]. Furthermore, the p53 protein is sensitive to ROS inducing DNA double-strand breaks via the ataxia telangiectasia mutated pathway [62]. It also regulates various target genes, which are engaged both in ROS/RNS generation (p53 inducible proteins family, COX-2 and NOS2) and in ROS/RNS clearance (glutathione peroxidase and superoxide dismutase) [59, 62].

The p53 protein represents defensive responses to carcinogens. However, the p53 gene has been found mutant across all cancer sites leading to dysregulation of downstream genes $[58,61]$. The p53 inducible protein
3 , as a prominent example, induces ROS generation in order to stimulate genotoxic stress that leads to apoptosis [61]. Most tumor-derived p53 mutants lead to an inactivation of p53 inducible protein 3, which promotes cancer cell survival [61]. Superoxide scavenger superoxide dismutase is another downstream protein of $\mathrm{p} 53$. It can be upregulated by physiological levels of p53 and shows an antioxidative ability to protect cells from apoptosis $[60,62]$. However, high levels of p53 induce superoxide dismutase downregulation which increases ROS concentration and promotes apoptosis [60, 62]. Superoxide dismutase is found overexpressed and is in favor of mitochondrial homeostasis in cancer cells [60].

\section{Activator protein 1 (AP-1)}

Activator protein 1 (AP-1) is also characterized by a basic leucine-zipper (bZIP) and can bind to 12-O-tetradecanoylphorbol-13-acetate (TPA) or cMAP response elements (CRE) to regulate gene expression [37, 63]. It comprises members from the FOS (c-FOS, FRA1, FRA2, FOSB), JUN (c-JUN, JUNB, JUND), ATF/CREB (CREB, ATF1-7, B-ATF, ATFa), MAF (c-MAF, MAFB, NRL, MAFF/G/K) and JDP (JDP1/2) subfamilies [63]. AP-1 is a dimeric complex. Its regulations include dimer composition, transcription, post-translational modification and interactions with other proteins [63]. It has been reported that oxidative stress is able to induce upregulation as well as downregulation of AP-1 activity by modifying AP-1 at the post-translational and post-transcriptional levels [37].

Target genes of AP-1 are involved in invasion, metastasis, proliferation, differentiation, survival and angiogenesis [63, 64]. However, AP-1 is a double-edged sword in tumorigenesis because its actions depend upon relative abundance of subfamily members [65]. It can be a pro-oncogenic or anti-oncogenic factor. A pro-oncogenic example is that c-JUN and JUNB promote uncontrolled cell division by inducing upregulation of the epidermal growth factor receptor [64, 65]. An anti-oncogenic example is that c-JUN can downregulate the expression of p53 resulting in inhibition of proliferation and stimulation of apoptosis [65].

\section{Forkhead box O (FOXO)}

The forkhead box O (FOXO) protein family is a subfamily of forkhead transcription factors. They participate in cell fate determination. There are 4 isoforms that have been identified in mammals: FOXO1, FOXO3a, FOXO4 and FOXO6. FOXO proteins are regulated by ROS and are implicated in regulation of intracellular redox status $[62,66,68]$. It has been shown that FOXO proteins can be inhibited by ROS via the PI3K and IKK pathways $[67,68]$. However, ROS can also act as an 
activator of the FOXO proteins by inducing activation of the MAPK pathways $[67,68]$. Target genes of FOXO proteins are devoted to multiple cellular activities, such as detoxification of ROS, cell cycle arrest and apoptosis $[66,68]$. At the early stage of cancer development, FOXO activity is inhibited by the activation of the PI3K-AKT pathway, which causes accumulation of ROS and drives cancer progression [67].

\section{Signal transducer and activator of transcription (STAT)}

Signal transducer and activator of transcription (STAT) proteins are transducers and transcription factors involved in the regulation of cellular inflammatory responses, cell survival and proliferation. Seven STAT proteins have been identified in mammals: STAT1-4, STAT5A, STAT5B and STAT6 [69, 70]. STAT proteins are induced by activation of cytokine-Janus kinase (JAK) signaling $[69,70]$. ROS/RNS have been shown to regulate STAT negatively or positively [69]. Oxidative stress may inhibit the cytokines and oxidize STAT and JAK resulting in inactivation of the cytokine-JAK-STAT pathway [69]. On the contrary, it has also been reported that $\mathrm{H}_{2} \mathrm{O}_{2}$ has the ability to activate the pathway via inhibition of tyrosine phosphatases and activation of tyrosine kinases [69]. Furthermore, intracellular redox status can be regulated by STAT proteins. For instance, STAT3 can migrate into mitochondria and upregulate ETC activity which leads to an increase in ROS production [69].

STAT proteins control inflammatory responses and are involved in cancer development [70]. STAT3 and STAT5 are upregulated in numerous types of cancer cells and promote cancer growth, angiogenesis and metastasis [70]. In particular, activation of STAT3 leads to expression of interleukin- 6 and COX-2 which mediate cancerpromoting immunity [70].

\section{Wnt/ß-catenin pathway}

The Wnt/ $\beta$-catenin signaling pathway is implicated in cell proliferation, cell adhesion and cell fate decision $[58,71,73]$. Under unstimulated condition, $\beta$-catenin is inactivated by forming a destruction complex with axin, adenomatous polyposis coli, glycogen synthase kinase 3 and casein kinase 1 [71, 72]. The Wnt protein, which consists of 19 isoforms, is an upstream machine in the pathway. Wnt can activate $\beta$-catenin transcriptional activity by binding to a Frizzled receptor and low-density lipoprotein receptor-related protein 5 and $6[71,72]$. ROS have been shown to exert a positive role in regulation of the Wnt/ $\beta$-catenin pathway through inhibiting the activity of a blocker of the Wnt/ $\beta$-catenin pathway, named nucleoredoxin. ROS are also involved in interactions between the Wnt/ $\beta$-catenin and downstream signaling pathways, such as p53 and FOXO [58]. It has been shown that the misregulation of the $\mathrm{Wnt} / \beta$-catenin pathway is associated with cancer development. Activating mutations of the Wnt/ $\beta$-catenin pathway components have been found in many types of cancer (e.g. hepatocellular cancer [73]), which benefits cancer growth [71-73]. For example, mutations in the $\beta$-catenin gene (CTNNB1) can lead to $\beta$-catenin overexpression.

\section{Apurinic/apyrimidinic endonuclease 1 (APE1)/ Redox effector factor-1 (Ref-1)}

Apurinic/apyrimidinic endonuclease 1 (APE1)/ Redox effector factor-1 (Ref-1) is a multifunctional protein which is ubiquitous in tissues [75]. It is involved in base excision repair of DNA damage and functions as a regulator in reductive activation of many transcription factors $[74,75]$. The redox status of reactive cysteine residues, control the transcriptional activity of APE1/ Ref-1 itself [74]. The C- and N- terminal region of APE1/ Ref-1 are responsible for DNA repair and the redox activity, respectively (Figure 6) [74]. In base excision repair pathways, APE1/Ref-1 behaves as an apurinic/ apyrimidinic endonuclease or as a 3'-phosphodiesterase and interacts with other DNA repair-related proteins $[74,75]$. It maintains genomic stability in normal cells. However, the base excision repair pathway also facilitates cancer cell survival, which drives cancer growth [74, 75]. As a co-activator of transcription factors, APE1/ Ref-1 controls the redox status of many transcription factors, including AP-1, NF- $\kappa$ B, p53, HIF-1, STAT3, Myb, PEBP2, HLF, NF-Y, Egr-1, PAX proteins, CBP/ p300 and others $[74,75]$. Through the activation of these transcription factors, APE1/Ref-1 is involved in cancer cell survival, proliferation, angiogenesis and apoptosis.

\section{Small mothers against decapentaplegic (Smad) proteins}

There are $8 \mathrm{Smad}$ proteins in humans. They are categorized into 3 subfamilies including receptor-regulated Smad (R-Smad) and common-partner Smad (Co-Smad) as well as inhibitory Smad (I-Smad). The R-Smad, with Smad1, Smad2, Smad3, Smad5 and Smad9, are the substrates of the receptors of the transforming growth factor- $\beta$ (TGF- $\beta$ ) family members. Smad4 is the only Co-Smad identified in human and serves as a common partner of R-Smad. It can interact with R-Smad forming functional transcriptional complexes. The TGF- $\beta / \mathrm{Smad}$ pathway takes part in a wide range of cellular activities, such as cell growth and apoptosis. The I-Smad subfamily members Smad6 and Smad7 function in negative regulation of the TGF- $\beta /$ Smad pathway. Furthermore, ROS can function as a regulator of the TGF- $\beta / \mathrm{Smad}$ pathways. It has been shown that ROS are involved in 
the crosstalk between the $\mathrm{p} 53$ and TGF- $\beta /$ Smad pathways [58]. Different Smad proteins members act differently in cancer cells. Even the same Smad protein can play a dual role in cancer development [76]. Smad2, which is regarded as a suppressor of cancer, has been observed inhibited in various types of cancer [76]. Smad7 has been reported to act as a pro-carcinogenic factor by sustaining colon cancer survival. However, the over-expression of Smad7 leads to an inhibition of metastasis [76].

\section{Other transcription factors}

For less prominent transcription factors we refer interested readers to other reviews. Yes-associated protein 1 , specificity protein 1 , aryl hydrocarbon receptor, early growth response protein 1, Glucocorticoid receptor, paired box 5 and 8 , transcription termination factor 1 and upstream stimulatory factor 1 are described in the review of Brigelius-Flohe and Flohe [6], E26 transformationspecific-1 in the review of Verschoor et al. [16] and nuclear factor of activated T-cells as well as transcriptional activator Myb in the review of Bansal and Kaushal [37].

\section{DISCUSSION}

\section{Summarizing overview on reduction-oxidation pathways}

The oxidative stress theory highlights the disruption of redox signaling caused by excessive oxidants. Intracellular ROS/RNS generating organelles are mitochondria, endoplasmic reticulum and peroxisomes. In addition several enzymes generate ROS/RNS, with NOX, COX, LOX and NOS as the most prominent enzymes. Of the reactive oxidants, highly reactive hydroxyl radical and superoxide anion can react with DNA exerting harmful effects on DNA bases and structure leading to mutations. ROS/RNS also switch "on" or "off" protein activity by mediating oxidation of certain reactive amino acid residues in proteins, such as cysteine and tyrosine residues. Oxidants induce redox modifications of protein kinases and phosphatases, which subsequently play roles in the regulation of transcription factors. The aberrant activation of transcription factors results in downregulated expression of target genes related to cellular transformation, cancer cell survival and proliferation, as well as cancer angiogenesis and invasion. Oxidants induce redox modifications of protein kinases and phosphatases, which subsequently activates transcription factors. The aberrant activation of transcription factors results in the deregulation of the target gene expression. However, most of the described pathways can exert both pro- and antiproliferative effects, depending on specific conditions.

\section{Opportunities for cancer prevention}

Cancer prevention strategies usually aim to decrease exposure to known cancer risk factors, such as smoking, and to increase exposure to preventive factors, such as foods with anti-proliferative effects. The main risk factor for cancer, smoking, in part also acts as a carcinogen by activating oxidative pathways [79]. Therefore, smoking cessation is also a successful cancer prevention target because cessation can help to regain redox balance. Preventive agents can be found in anti-oxidative ingredients of foods and there are interesting results from investigations about actions of food ingredients on redox signaling pathways.

\section{Targeting mitochondria and ROS/RNS generating enzymes}

Research has focused on dietary phytochemicals, which act as antioxidants in mitochondria. For instance, quercetin is a natural flavonoid compound which can be found in many fruits and vegetables. A study in Caco-2 cells showed that it protects complex I from inactivation, which has been proposed to increase the production of ROS [80]. As mentioned previously, NOX, iNOS and COX-2 are over-expressed in neoplasms. Curcumin is another phytochemical that has been reported to suppress the activation of these enzymes [81, 82]. In summary, foods rich in flavonoids, such as onions, and curcumin, such as "mango ginger" (curcuma amada), could be helpful and safe agents in cancer prevention.

\section{Targeting signal transduction cascades kinases/ phosphatases}

Myo-inositol is a sugar alcohol, which can be found in whole grains, seeds and fruits. It has been reported to be an inhibitor of AKT in vitro and shows chemoprevention activity in smokers [83]. Another important target for chemoprevention is the RAS-RAF-MEK-ERK pathway, which is also frequently overactivated in cancers. Recently, both in vitro and in vivo studies have shown that the kinase activity of EKR $1 / 2$ is inhibited by grifolin, an isolate of the mushroom [84]. In addition, it has been reported in biological research that quercetin might have an effect on the activity of intracellular ROS/RNS generating enzymes via inhibiting MEK1 activity [85]. However, epidemiological evidence on the association of quercetin-rich food intake with cancer risk is still inconclusive [86]. Nevertheless, promising mechanisms acting via the redox signal transduction cascades kinases/ phosphatases have been identified by which ingredients of whole grains, seeds, fruits and mushrooms can contribute to cancer prevention. 


\section{Targeting transcription factors}

Sulforaphane and dithiolethiones act as inducers of $\mathrm{Nrf} 2$ and have been considered as cancer chemopreventive agents [87]. The major dietary sources of sulforaphane and dithiolethiones are cruciferous vegetables, such as broccoli. Other redox-sensitive transcription factors, such as NF- $\mathrm{kB}$ and $\mathrm{AP}-1$, are also promising targets for cancer prevention. In addition, epigallocatechin gallate has been identified as a major antioxidant phenolic compound in green tea. It has been found to downregulate the activities of NF-KB and AP-1 in animal models [88]. In summary, cruciferous vegetables and green tea could be helpful for cancer prevention due to the beneficial effects on transcription factors.

\section{Cancer treatment opportunities}

\section{Targeting mitochondria and ROS/RNS generating enzymes}

Since ROS lead to genomic instability and regulate protein function, intracellular oxidant sources are also considered as promising targets in cancer therapy. As the mitochondrial ETC generates more ROS in cancer cells, ETC inhibitors are one of the mitochondria-targeted therapeutic strategies. However, high levels of ROS make cancer cells more prone to apoptosis than normal cells and inhibiting the ETC may have unwanted proliferative side effects.

A different strategy is to inhibit oxidant-generating enzymes in order to prevent and treat cancer [21, 89]. In recent decades, efforts have been dedicated to the development of the inhibitors. For example, diphenylene iodonium is a small-molecule non-selective inhibitor and more inhibitors of NOX have been identified, recently [90]. However, most of them are not specific to NOX isoforms [91]. COX and LOX inhibitors, which are usually used as anti-inflammatory drugs, also show potential in cancer prevention or treatment $[92,93]$. The COX-2 selective inhibitor Celecoxib is currently being tested in trials against lung cancer [94]. In terms of NOS, both inducers and inhibitors of NOS could be agents in cancer treatment depending on the context [26]. To be specific, fenretinide can induce iNOS-derived NO production leading to breast cancer cell death [26]. In contrast, L-NAME, an inhibitor of NOS, has been shown to reduce the production of vascular endothelial growth factor in ovarian cancer cells [95].

\section{Targeting signal transduction cascades kinases/ phosphatases}

This systematic review also provides an overview on the redox dependent signal transduction pathways in cancer development. Blocking components of signal transduction are a further major therapeutic strategy for developing cancer treatments. Inhibitors are currently being developed that target kinases or phosphatases of signaling pathways [32, 38, 39, 42]. Epidermal growth factor receptors, a subfamily of RTKs, are targeted by inhibitors and monoclonal antibodies which may prevent proliferation and angiogenesis in multiple cancer types, including breast cancer, colorectal cancer and lung cancer [38]. Furthermore, NRTK inhibitors are being developed for the treatment of cancer. For example, an inhibitor of $\mathrm{Abl}$ fusion protein has been tested for the treatment of chronic myelogenous leukemia [39]. The RAS-RAFMEK-ERK pathway, one of the extensively studied MAPK pathways, is also a target of novel cancer therapies which focus' on blocking this pathway via small-molecule inhibitors [96]. Furthermore, the first clinical trials have shown that inhibitors of the PI3K pathway components could be effective in various cancers [97].

\section{Targeting transcription factors}

Misregulation of transcription factors is a common cause of many diseases including cancer [98]. Some hyperactivated transcription factors in cancer cells have been linked with chemotherapy and radiotherapy resistance up to treatment failure [99]. Therefore, inhibition of transcription factors may be a useful strategy to increase the effectiveness of cancer therapies. For example, inhibitors are being developed to block STATs which are persistently activated in a wide range of cancers [100]. However, some transcription factors are commonly downregulated in cancer cells, mostly because of genetic aberrations [101]. Therefore, the therapeutic strategy here is to elevate the function of transcription factors or to stabilize genes encoding transcription factors. As an outstanding example, TP53 is often found mutated leading to downregulation of $\mathrm{p} 53$, which suppresses tumor growth and progression [58]. Nutlins, an inhibitor of a p53 blocker, has been shown to suppress tumor growth in preclinical studies by induction of p53-mediated apoptosis [101].

\section{Further research needs}

The research area of redox signaling pathways involved in cancer development and progress is very active at the moment and identification of promising new drug targets as well as novel drug developments can be expected from future research. Although components of the redox signaling pathways are promising targets for cancer therapy and prevention, we still have a long way to go to put strategy into practice. Some challenges keep drug development research from advancing.

Firstly, redox signaling pathways concerned herein are complex and function differently under different conditions and in different cell types. Further basic research is needed to investigate mechanisms of redox signaling function in normal and cancer contexts. 
Second, because of the high complexity of redox signaling pathways, manipulating them can have multiple actions that may result in severe adverse drug reactions. Clinical trials conducted by the pharmaceutical industry are therefore at high risk of failure because novel drugs may have an unfavorable benefit-risk ratio. However, this should not discourage drug development in the area of redox signaling pathways because it includes promising drug targets involved in both cancer development and progression. Further early stage clinical trials are required to assess the benefit-risk ratio of recently developed drugs and to evaluate novel drugs.

\section{CONCLUSIONS}

In summary, this systematic review summarizes the 20 most frequently described redox-regulation pathways, which play a role in cancer formation, including ROS/ RNS-generating organelles and enzymes, kinases/ phosphatases in signal transduction cascades and transcription factors. The dysfunction of ROS/RNSgenerating organelles and enzymes leads to ROS/RNS over-production, which induce oxidative stress. The kinases and phosphatases can be activated or inhibited by ROS/RNS and subsequently regulate the expression of transcription factors. However, whether ROS/RNS promote or suppress cancer development depends on cell context. Nevertheless, the area of redox signaling pathways includes promising drug targets involved in both cancer development and progression and further basic and clinical research is needed.

\section{MATERIALS AND METHODS}

\section{Search strategy}

A systematic search for literature reviews was performed in the electronic databases ISI Web of Knowledge (Thomson Scientific Technical Support, New York) and MEDLINE (Ovid Technologies, New York). Various combinations and phrases of the search terms "neoplasms", "oxidative stress", "free radicals" and "signal transduction" were used to find relevant publications published between January 1st, 2005 and October 20th, 2015 (Appendix A). Literature from the last ten years was considered comprehensive enough because the main discoveries were made in this time, and older, still up to date discoveries are still reviewed in more recent high-quality reviews on the topic, which we included in the systematic review. Furthermore, we filtered out publications not related to humans and other publication types than reviews. The search strategy in PubMed is shown in Appendix A. Reference lists of review articles which did not meet any exclusion criterion were checked in order to identify further articles potentially eligible for inclusion. In addition, a specific search for each redox pathway mentioned in the so far identified reviews was conducted by combining a search review for the pathway with the phases for the term neoplasms. The EndNote X7.4 software (Thompson Reuters, New York) was used throughout the literature reviews search and selection process.

\section{Eligibility criteria}

After eliminating duplicate publications, we reviewed each title and abstract of the remaining to determine whether the article was possibly relevant for the topic of the systematic review. Papers were excluded if they (1) were an original article, (2) were not related to humans, (3) did not mention any pathway for the development of cancer, (4) described a pathway in which free radicals and redox processes were not involved, or (5) described external sources of oxidative or reductive mechanisms as the main topic (e.g. nutrients, therapeutics and toxic substances). At the stage of full-text selection, the same selection criteria were applied.

\section{Appraisal of the literature and extraction of information}

Each included review was assessed by using a selfdeveloped information quality score by subjectively rating the comprehensiveness and quality of information in 4 domains: Description of the redox regulation ( $0-3$ points), description of the mechanism(s) leading to cancer (0-3 points), description of the regulator(s) of the pathway(s) (0-2 points) and description of the interaction of the main pathway of interest with other pathways (0-2 points). The maximum possible score is 10 points and reviews with a score of 6 or higher were finally included in the present review. Reviews with lower information quality scores, not being used for the present review are shown in Appendix B.

The pathways identified in the reviews and the frequencies of their appearance in the included reviews were counted. In order to focus on the most prominent pathways, we review only those pathways described 5 times or more. For readers with interest in less frequently reviewed pathways, we cite the review articles with information about these pathways.

\section{Author contributions}

BS designed the study and XG performed the systematic screening of the literature, evaluated studies and extracted the information. XG drafted the manuscript and BS revised the manuscript critically. All authors read 
and approved the final manuscript.

\section{ACKNOWLEDGMENTS}

We apologize to the authors whose papers could not be cited due to space limitations. The authors are indebted to Professor Hermann Brenner, Dr. Michael Hoffmeister and Dr. Volker Arndt for comments and suggestions and Prudence Carr for English language editing.

\section{CONFLICTS OF INTEREST}

The authors have no conflicts of interest to disclose

\section{FUNDING}

This study was supported by the German Research Foundation (Deutsche Forschungsgemeinschaft, DFG, grant No. SCHO 1545/3-1) to BS and by China scholarship council to XG.

\section{REFERENCES}

1. Kang SW, Lee S, Lee EK. ROS and energy metabolism in cancer cells: alliance for fast growth. Arch Pharm Res. 2015; 38:338-45.

2. Jones DP. Radical-free biology of oxidative stress. Am J Physiol Cell Physiol. 2008; 295:C849-68.

3. Valko M, Leibfritz D, Moncol J, Cronin MT, Mazur M, Telser J. Free radicals and antioxidants in normal physiological functions and human disease. Int J Biochem Cell Biol. 2007; 39:44-84.

4. Miller TW, Isenberg JS, Roberts DD. Molecular regulation of tumor angiogenesis and perfusion via redox signaling. Chem Rev. 2009; 109:3099-124.

5. Holmström KM, Finkel T. Cellular mechanisms and physiological consequences of redox-dependent signalling. Nat Rev Mol Cell Biol. 2014; 15:411-21.

6. Brigelius-Flohé R, Flohé L. Basic principles and emerging concepts in the redox control of transcription factors. Antioxid Redox Signal. 2011; 15:2335-81.

7. Gius D, Spitz DR. Redox signaling in cancer biology. Antioxid Redox Signal. 2006; 8:1249-1252.

8. Sosa V, Moliné T, Somoza R, Paciucci R, Kondoh H, LLeonart ME. Oxidative stress and cancer: an overview. Ageing Res Rev. 2013; 12:376-90.

9. Reuter S, Gupta SC, Chaturvedi MM, Aggarwal BB. Oxidative stress, inflammation, and cancer: how are they linked? Free Radic Biol Med. 2010; 49:1603-16.

10. Fiaschi T, Chiarugi P. Oxidative stress, tumor microenvironment, and metabolic reprogramming: a diabolic liaison. Int J Cell Biol. 2012; 2012:762825.

11. Zhou D, Shao L, Spitz DR. Reactive oxygen species in normal and tumor stem cells. Adv Cancer Res. 2014;
122:1-67.

12. Yang S, Pinney SM, Mallick P, Ho SM, Bracken B, $\mathrm{Wu}$ T. Impact of Oxidative Stress Biomarkers and Carboxymethyllysine (an Advanced Glycation End Product) on Prostate Cancer: A Prospective Study. Clin Genitourin Cancer. 2015; 13:e347-51.

13. Loft S, Olsen A, Møller P, Poulsen HE, Tjønneland A. Association between 8-oxo-7,8-dihydro-2'-deoxyguanosine excretion and risk of postmenopausal breast cancer: nested case-control study. Cancer Epidemiol Biomarkers Prev. 2013; 22:1289-96.

14. Pennington JD, Wang TJ, Nguyen P, Sun L, Bisht K, Smart D, Gius D. Redox-sensitive signaling factors as a novel molecular targets for cancer therapy. Drug Resist Updat. 2005; 8:322-330.

15. Tokarz P, Blasiak J. Role of mitochondria in carcinogenesis. Acta Biochim Pol. 2014; 61:671-78.

16. Verschoor ML, Wilson LA, Singh G. Mechanisms associated with mitochondrial-generated reactive oxygen species in cancer. Can J Physiol Pharmacol. 2010; 88:20419.

17. Wallace DC. Mitochondria and cancer. Nat Rev Cancer. 2012; 12:685-98.

18. Meitzler JL, Antony S, Wu Y, Juhasz A, Liu H, Jiang G, Lu J, Roy K, Doroshow JH. NADPH oxidases: a perspective on reactive oxygen species production in tumor biology. Antioxid Redox Signal. 2014; 20:2873-2889.

19. Landry WD, Cotter TG. ROS signalling, NADPH oxidases and cancer. Biochem Soc Trans. 2014; 42:934-38.

20. Jiang F, Zhang Y, Dusting GJ. NADPH oxidase-mediated redox signaling: roles in cellular stress response, stress tolerance, and tissue repair. Pharmacol Rev. 2011; 63:21842.

21. Speed N, Blair IA. Cyclooxygenase- and lipoxygenasemediated DNA damage. Cancer Metastasis Rev. 2011; 30:437-47.

22. Furstenberger G, Krieg P, Muller-Decker K, Habenicht AJ. What are cyclooxygenases and lipoxygenases doing in the driver's seat of carcinogenesis? Int J Cancer. 2006; 119:2247-2254.

23. Korbecki J, Baranowska-Bosiacka I, Gutowska I, Chlubek D. The effect of reactive oxygen species on the synthesis of prostanoids from arachidonic acid. J Physiol Pharmacol. 2013; 64:409-421.

24. Knab LM, Grippo PJ, Bentrem DJ. Involvement of eicosanoids in the pathogenesis of pancreatic cancer: the roles of cyclooxygenase-2 and 5-lipoxygenase. World J Gastroenterol. 2014; 20:10729-39.

25. Fukumura D, Kashiwagi S, Jain RK. The role of nitric oxide in tumour progression. Nat Rev Cancer. 2006; 6:521-34.

26. Vannini F, Kashfi K, Nath N. The dual role of iNOS in cancer. Redox Biol. 2015; 6:334-43.

27. Bogdan C. Nitric oxide synthase in innate and adaptive immunity: an update. Trends Immunol. 2015; 36:161-78. 
28. Liu W, Phang JM. Proline dehydrogenase (oxidase) in cancer. Biofactors. 2012; 38:398-406.

29. McCubrey JA, Lahair MM, Franklin RA. Reactive oxygen species-induced activation of the MAP kinase signaling pathways. Antioxid Redox Signal. 2006; 8:1775-1789.

30. Kim EK, Choi EJ. Compromised MAPK signaling in human diseases: an update. Arch Toxicol. 2015; 89:867-82.

31. Barthel A, Klotz LO. Phosphoinositide 3-kinase signaling in the cellular response to oxidative stress. Biol Chem. 2005; 386:207-16

32. Yang Q, Lee JD. Targeting the BMK1 MAP kinase pathway in cancer therapy. Clin Cancer Res. 2011; 17:3527-3532.

33. Wagner EF, Nebreda AR. Signal integration by JNK and p38 MAPK pathways in cancer development. Nat Rev Cancer. 2009; 9:537-49.

34. Dhillon AS, Hagan S, Rath O, Kolch W. MAP kinase signalling pathways in cancer. Oncogene. 2007; 26:327990.

35. Yousefi B, Samadi N, Ahmadi Y. Akt and p53R2, partners that dictate the progression and invasiveness of cancer. DNA Repair (Amst). 2014; 22:24-29.

36. Martini M, De Santis MC, Braccini L, Gulluni F, Hirsch E. PI3K/AKT signaling pathway and cancer: an updated review. Ann Med. 2014; 46:372-83.

37. Bansal M, Kaushal N. Cell signalling and gene regulation by oxidative stress. In: Bansal M, Kaushal N, editors. Oxidative Stress Mechanisms and their Modulation. Springer India. 2014

38. Regad T. Targeting RTK Signaling Pathways in Cancer. Cancers (Basel). 2015; 7:1758-84.

39. Gocek E, Moulas AN, Studzinski GP. Non-receptor protein tyrosine kinases signaling pathways in normal and cancer cells. Crit Rev Clin Lab Sci. 2014; 51:125-37.

40. Chiarugi P. PTPs versus PTKs: the redox side of the coin. Free Radic Res. 2005; 39:353-64.

41. Tonks NK. Protein tyrosine phosphatases: from genes, to function, to disease. Nat Rev Mol Cell Biol. 2006; 7:83346.

42. Ostman A, Hellberg C, Böhmer FD. Protein-tyrosine phosphatases and cancer. Nat Rev Cancer. 2006; 6:307-20.

43. Garg R, Benedetti LG, Abera MB, Wang H, Abba M, Kazanietz MG. Protein kinase $\mathrm{C}$ and cancer: what we know and what we do not. Oncogene. 2014; 33:5225-37.

44. Giorgi C, Agnoletto C, Baldini C, Bononi A, Bonora M, Marchi S, Missiroli S, Patergnani S, Poletti F, Rimessi A, Zavan B, Pinton P. Redox control of protein kinase C: celland disease-specific aspects. Antioxid Redox Signal. 2010; 13:1051-1085.

45. Qin F, Tian J, Zhou D, Chen L. Mst1 and Mst2 kinases: regulations and diseases. Cell Biosci. 2013; 3:31.

46. Leinonen HM, Kansanen E, Pölönen P, Heinäniemi M, Levonen AL. Role of the Keap1-Nrf2 pathway in cancer. Adv Cancer Res. 2014; 122:281-320.
47. Shelton P, Jaiswal AK. The transcription factor NF-E2related factor 2 (Nrf2): a protooncogene? FASEB J. 2013; 27:414-23.

48. Na HK, Surh YJ. Oncogenic potential of Nrf2 and its principal target protein heme oxygenase-1. Free Radic Biol Med. 2014; 67:353-65.

49. Xiang M, Namani A, Wu S, Wang X. Nrf2: bane or blessing in cancer? J Cancer Res Clin Oncol. 2014; 140:1251-59.

50. Parri M, Chiarugi P. Redox molecular machines involved in tumor progression. Antioxid Redox Signal. 2013; 19:182845.

51. Oeckinghaus A, Ghosh S. The NF-kappaB family of transcription factors and its regulation. Cold Spring Harb Perspect Biol. 2009; 1:a000034.

52. Aggarwal BB, Sethi G, Nair A, Ichikawa H. Nuclear factorkappa B: A holy grail in cancer prevention and therapy. Curr Signal Transduct Ther. 2006; 1:25-52.

53. Sarkar FH, Li Y, Wang Z, Kong D. NF-kappaB signaling pathway and its therapeutic implications in human diseases. Int Rev Immunol. 2008; 27:293-319.

54. Duan C. Hypoxia-inducible factor 3 biology: complexities and emerging themes. Am J Physiol Cell Physiol. 2016; 310:C260-69.

55. Galanis A, Pappa A, Giannakakis A, Lanitis E, Dangaj D, Sandaltzopoulos R. Reactive oxygen species and HIF-1 signalling in cancer. Cancer Lett. 2008; 266:12-20.

56. Zhao J, Du F, Shen G, Zheng F, Xu B. The role of hypoxiainducible factor- 2 in digestive system cancers. Cell Death Dis. 2015; 6:e1600.

57. Movafagh S, Crook S, Vo K. Regulation of hypoxiainducible factor-1a by reactive oxygen species: new developments in an old debate. J Cell Biochem. 2015; 116:696-703.

58. Ladelfa MF, Toledo MF, Laiseca JE, Monte M. Interaction of p53 with tumor suppressive and oncogenic signaling pathways to control cellular reactive oxygen species production. Antioxid Redox Signal. 2011; 15:1749-1761.

59. Maillet A, Pervaiz S. Redox regulation of $\mathrm{p} 53$, redox effectors regulated by p53: a subtle balance. Antioxid Redox Signal. 2012; 16:1285-1294.

60. Pani G, Galeotti T. Role of MnSOD and p66shc in mitochondrial response to p53. Antioxid Redox Signal.2011; 15:1715-1727.

61. Kotsinas A, Aggarwal V, Tan EJ, Levy B, Gorgoulis VG. PIG3: a novel link between oxidative stress and DNA damage response in cancer. Cancer Lett. 2012; 327:97-102.

62. Vurusaner B, Poli G, Basaga H. Tumor suppressor genes and ROS: complex networks of interactions. Free Radic Biol Med. 2012; 52:7-18.

63. Kappelmann M, Bosserhoff A, Kuphal S. AP-1/c-Jun transcription factors: regulation and function in malignant melanoma. Eur J Cell Biol. 2014; 93:76-81.

64. Karamouzis MV, Konstantinopoulos PA, Papavassiliou AG. 
The activator protein-1 transcription factor in respiratory epithelium carcinogenesis. Mol Cancer Res. 2007; 5:10920.

65. Eferl R, Wagner EF. AP-1: a double-edged sword in tumorigenesis. Nat Rev Cancer. 2003; 3:859-68.

66. Wątroba M, Maślińska D, Maśliński S. Current overview of functions of FoxO proteins, with special regards to cellular homeostasis, cell response to stress, as well as inflammation and aging. Adv Med Sci. 2012; 57:183-95.

67. Myatt SS, Brosens JJ, Lam EW. Sense and sensitivity: FOXO and ROS in cancer development and treatment. Antioxid Redox Signal. 2011; 14:675-687.

68. Storz P. Forkhead homeobox type O transcription factors in the responses to oxidative stress. Antioxid Redox Signal. 2011; 14:593-605.

69. Bourgeais J, Gouilleux-Gruart V, Gouilleux F. Oxidative metabolism in cancer: A STAT affair? JAK-STAT. 2013; 2:e25764.

70. Yu H, Pardoll D, Jove R. STATs in cancer inflammation and immunity: a leading role for STAT3. Nat Rev Cancer. 2009; 9:798-809.

71. MacDonald BT, Tamai K, He X. Wnt/beta-catenin signaling: components, mechanisms, and diseases. Dev Cell. 2009; 17:9-26.

72. Saito-Diaz K, Chen TW, Wang X, Thorne CA, Wallace HA, Page-McCaw A, Lee E. The way Wnt works: components and mechanism. Growth Factors. 2013; 31:1-31.

73. Monga SP. Role of $\mathrm{Wnt} / \beta$-catenin signaling in liver metabolism and cancer. Int J Biochem Cell Biol. 2011; 43:1021-29.

74. Tell G, Quadrifoglio F, Tiribelli C, Kelley MR. The many functions of APE1/Ref-1: not only a DNA repair enzyme. Antioxid Redox Signal. 2009; 11:601-620.

75. Thakur S, Sarkar B, Cholia RP, Gautam N, Dhiman M, Mantha AK. APE1/Ref-1 as an emerging therapeutic target for various human diseases: phytochemical modulation of its functions. Exp Mol Med. 2014; 46:e106.

76. Samanta D, Datta PK. Alterations in the Smad pathway in human cancers. Front Biosci (Landmark Ed). 2012; 17:1281-93.

77. Nakanishi A, Wada Y, Kitagishi Y, Matsuda S. Link between PI3K/AKT/PTEN Pathway and NOX Proteinin Diseases. Aging Dis. 2014; 5:203-11.

78. Tauro M, McGuire J, Lynch CC. New approaches to selectively target cancer-associated matrix metalloproteinase activity. Cancer Metastasis Rev. 2014; 33:1043-57.

79. Lowe FJ, Luettich K, Gregg EO. Lung cancer biomarkers for the assessment of modified risk tobacco products: an oxidative stress perspective. Biomarkers. 2013; 18:183-195.

80. Carrasco-Pozo C, Mizgier ML, Speisky H, Gotteland M. Differential protective effects of quercetin, resveratrol, rutin and epigallocatechin gallate against mitochondrial dysfunction induced by indomethacin in Caco-2 cells. Chem Biol Interact. 2012; 195:199-205.

81. Murakami A, Ohigashi H. Targeting NOX, INOS and COX-2 in inflammatory cells: chemoprevention using food phytochemicals. Int J Cancer. 2007; 121:2357-63.

82. Gupta SC, Patchva S, Aggarwal BB. Therapeutic roles of curcumin: lessons learned from clinical trials. AAPS J. 2013; 15:195-218.

83. Han W, Gills JJ, Memmott RM, Lam S, Dennis PA. The chemopreventive agent myoinositol inhibits Akt and extracellular signal-regulated kinase in bronchial lesions from heavy smokers. Cancer Prev Res (Phila). 2009; 2:370 76.

84. Luo X, Yu X, Liu S, Deng Q, Liu X, Peng S, Li H, Liu $\mathrm{J}$, Cao Y. The role of targeting kinase activity by natural products in cancer chemoprevention and chemotherapy (Review). Oncol Rep. 2015; 34:547-54. Review

85. Lee KW, Kang NJ, Heo YS, Rogozin EA, Pugliese A, Hwang MK, Bowden GT, Bode AM, Lee HJ, Dong Z. Raf and MEK protein kinases are direct molecular targets for the chemopreventive effect of quercetin, a major flavonol in red wine. Cancer Res. 2008; 68:946-55.

86. World Cancer Research Fund, American Institute for Cancer Research. Food, Nutrition, Physical Activity, and the Prevention of cancer: a Global Perspective. Washington (DC): AICR; 2007. pp. 537

87. Abed DA, Goldstein M, Albanyan H, Jin H, Hu L. Discovery of direct inhibitors of Keap1-Nrf2 proteinprotein interaction as potential therapeutic and preventive agents. Acta Pharm Sin B. 2015; 5:285-99.

88. Singh BN, Shankar S, Srivastava RK. Green tea catechin, epigallocatechin-3-gallate (EGCG): mechanisms, perspectives and clinical applications. Biochem Pharmacol. 2011; 82:1807-21.

89. Bonner MY, Arbiser JL. Targeting NADPH oxidases for the treatment of cancer and inflammation. Cell Mol Life Sci. 2012; 69:2435-42.

90. Harrison IP, Selemidis S. Understanding the biology of reactive oxygen species and their link to cancer: NADPH oxidases as novel pharmacological targets. Clin Exp Pharmacol Physiol. 2014; 41:533-42.

91. Cifuentes-Pagano E, Meijles DN, Pagano PJ. The quest for selective nox inhibitors and therapeutics: challenges, triumphs and pitfalls. Antioxid Redox Signal. 2014; 20:2741-54.

92. Menna C, Olivieri F, Catalano A, Procopio A. Lipoxygenase inhibitors for cancer prevention: promises and risks. Curr Pharm Des. 2010; 16:725-33.

93. Aparoy P, Reddy KK, Reddanna P. Structure and ligand based drug design strategies in the development of novel 5- LOX inhibitors. Curr Med Chem. 2012; 19:3763-78.

94. Liu R, Xu KP, Tan GS. Cyclooxygenase-2 inhibitors in lung cancer treatment: bench to bed. Eur J Pharmacol. 2015; 
769:127-33.

95. Malone JM, Saed GM, Diamond MP, Sokol RJ, Munkarah AR. The effects of the inhibition of inducible nitric oxide synthase on angiogenesis of epithelial ovarian cancer. Am J Obstet Gynecol. 2006; 194:1110-16.

96. Santarpia L, Lippman SM, El-Naggar AK. Targeting the MAPK-RAS-RAF signaling pathway in cancer therapy. Expert Opin Ther Targets. 2012; 16:103-19.

97. Rodon J, Dienstmann R, Serra V, Tabernero J. Development of PI3K inhibitors: lessons learned from early clinical trials.
Nat Rev Clin Oncol. 2013; 10:143-53.

98. Lee TI, Young RA. Transcriptional regulation and its misregulation in disease. Cell. 2013; 152:1237-51.

99. Darnell JE Jr. Transcription factors as targets for cancer therapy. Nat Rev Cancer. 2002; 2:740-49.

100. Miklossy G, Hilliard TS, Turkson J. Therapeutic modulators of STAT signalling for human diseases. Nat Rev Drug Discov. 2013; 12:611-29.

101. Bhagwat AS, Vakoc CR. Targeting Transcription Factors in Cancer. Trends Cancer. 2015; 1:53-65. 